\title{
Síndrome oculoglandular de Parinaud causada por esporotricose
}

\section{Parinaud's oculoglandular syndrome caused by Sporotrichosis}

Alexandre Sampaio de Abreu Ribeiro', Tiago Bisol'2, Marcela Sant'Ana Menezes ${ }^{3}$

\section{Resumo}

A síndrome oculoglandular de Parinaud é uma doença ocular rara causada por diferentes agentes etiológicos, entre eles bactérias, vírus e fungos. É caracterizada por uma conjuntivite granulomatosa, acompanhada de linfadenopatia pré-auricular adjacente e pode trazer sequelas caso não seja prontamente tratada. Neste artigo é relatado o caso de uma jovem técnica de enfermagem e estudante de medicina veterinária apresentando a síndrome oculoglandular de Parinaud causada pelo fungo Sporothrix schenkii após contaminação com gatos infectados. Sua apresentação clínica e evolução desfavorável até o correto diagnóstico etiológico e instituição do tratamento específico, ressaltam a importância da investigação laboratorial em casos de evolução atípica da doença.

Descritores: Conjuntivite bacteriana/diagnóstico; Conjuntivite bacteriana/etiologia Granuloma/diagnóstico; Granuloma/etiologia; Doença da arranhadura de gato/complicações; Bartonella henselae; Esporotricose

\footnotetext{
${ }^{1}$ Médico Residente do $3^{\circ}$ ano do Hospital Central da Aeronáutica - HCA - Rio de Janeiro (RJ), Brasil;

${ }^{2}$ Professor assistente de pós-graduação em Oftalmologia pela Pontifícia Universidade Católica do Rio de Janeiro - PUC-RJ; Membro do corpo clínico do Hospital São Vicente de Paulo; Membro do Corpo clínico do Instituto de Diagnóstico e Terapia Ocular do Rio de Janeiro - IDTO - Rio de Janeiro (RJ), Brasil;

${ }^{3}$ Médica Residente do $2^{\circ}$ ano do Hospital Central da Aeronáutica - HCA - Rio de Janeiro - Rio de Janeiro (RJ), Brasil.

Trabalho foi realizado no Hospital Central da Aeronáutica - HCA - Rio de Janeiro (RJ), Brasil.
} 


\section{INTRODUÇÃO}

A síndrome oculoglandular de Parinaud (SOP) foi originalmente descrita como condição clínica rara que consiste em uma conjuntivite granulomatosa unilateral, acompanhada de linfadenopatia satélite pré-auricular ou submandibular ${ }^{(1)}$.

Diversos trabalhos publicados ao longo dos anos demonstraram que a SOP tem como principal agente etiológico a Bartonella hanselae (2), causadora da Bartonellose, também conhecida por doença da arranhadura do gato, descrita inicialmente por Debre em 1950. Trata-se de uma doença infecciosa benigna que geralmente se desenvolve após o contato ou arranhadura de gato doméstico (Felis sylvestris catus).

Entretanto, muitos outros organismos também podem ser causadores da SOP, como vírus, fungos, parasitas e microbactérias, sendo esses mais raramente encontrados.

Relatamos aqui um caso de Síndrome oculoglandular de Parinaud causada pelo fungo Sporothrix schenckii, agente etiológico de poucas descrições na literatura, sua apresentação, diagnóstico laboratorial e resposta à terapêutica específica.

\section{Relato do Caso}

L. S.P., feminina, 34 anos, parda, natural do Rio de Janeiro, técnica de enfermagem e estudante de medicina veterinária.

No dia 28 de abril de 2008 procurou o Serviço de Oftalmologia do Hospital Central da Aeronáutica, referindo ter notado, no mesmo dia, a presença de uma "le-

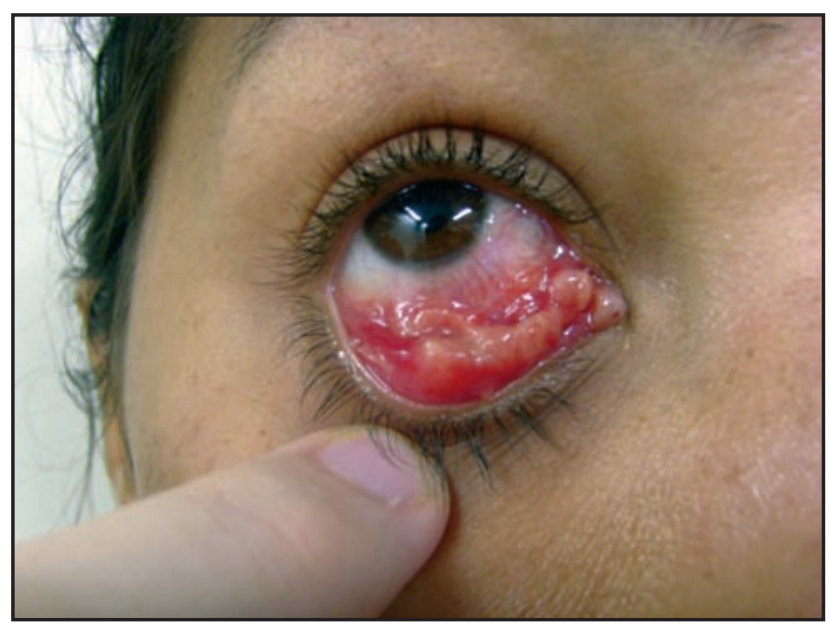

Figura 1: Nódulos na conjuntiva tarsal inferior. são em seu olho direito", sem queixas sintomáticas associadas e negando alteração de acuidade visual.

Relatou em anamnese dirigida história prévia de tuberculose pulmonar tratada um ano antes e episódio de pequeno trauma com corpo estranho no mesmo olho uma semana antes do aparecimento dos sintomas, sem sequelas. Referiu também que acompanhava o tratamento médico veterinário de quatro gatos de estimação, que apresentavam lesões infectadas pelo corpo, sem diagnóstico etiológico.

Ao exame, apresentou acuidade visual sem correção de 20/20 para longe e Jaeger I para perto em ambos os olhos, motilidade extrínseca normal e ortoforia para longe e perto. À biomicroscopia, observou-se em olho direito pequena lesão arredondada e hiperemiada, de base séssil, consistência macia e indolor à palpação, em conjuntiva tarsal inferior centralmente, medindo meio centímetro $(\mathrm{cm})$, com discreta quantidade de secreção mucóide. O exame biomicroscópico do olho esquerdo era normal. A tonometria de aplanação era de $13 \mathrm{mmHg}$ em ambos os olhos e a fundoscopia não evidenciava alterações retinianas ou vítreas nos dois olhos. Foi feito o diagnóstico clínico de granuloma piogênico e iniciado tratamento com colírio de dexametasona $1 \%$, quatro vezes ao dia e lubrificante.

Após cinco dias de tratamento, retornou com queixa de piora do quadro, relatando desconforto local e hiperemia. O exame evidenciou o surgimento de vários nódulos pequenos acompanhados de reação folicular em conjuntiva tarsal inferior (Figura 1) e superior, além de linfonodomegalia pré-auricular ipsilateral endurecida e dolorosa, de $2,0 \mathrm{~cm}$. Tais evidências apontaram para o

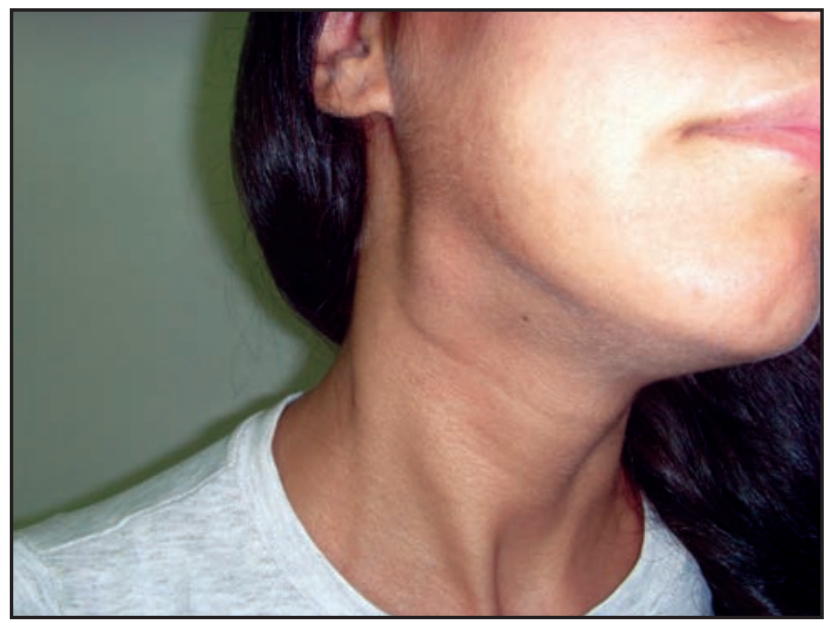

Figura 2: Linfonodomegalia submandibular 


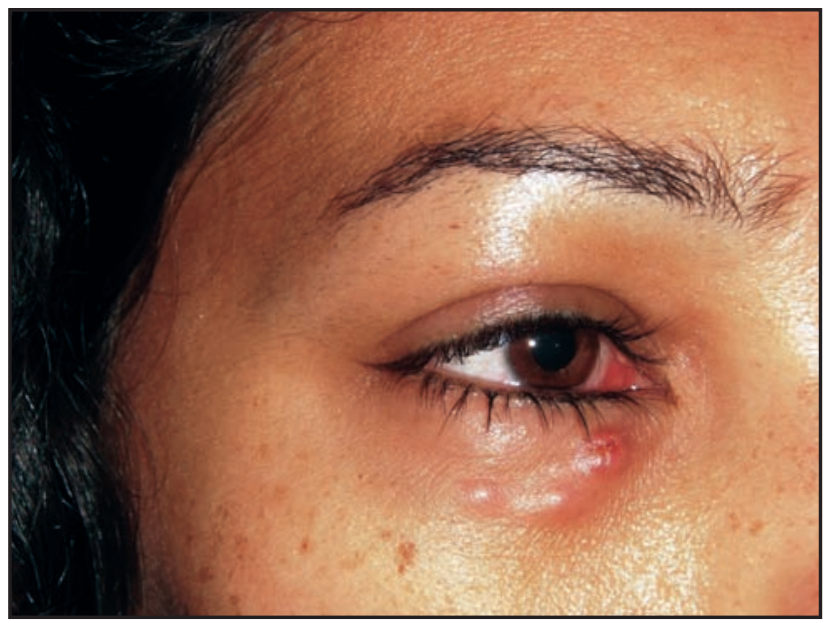

Figura 3: Lesões externas, tipo erupções, em pálpebra inferior

diagnóstico de Síndrome oculoglandular de Parinaud.

Iniciou-se, então, tratamento medicamentoso com azitromicina por via oral para doença da arranhadura-dogato (Bartonellose), baseando-se tanto na história de convívio com dezessete gatos em domicílio, bem como na alta incidência de bartonellose como agente etiológico da SOP.

Após sete dias, a paciente evoluiu com agravamento do quadro, aumento considerável das lesões conjuntivais e surgimento de linfonodomegalia submandibular à direita (Figura 2), blefaroedema, aumento da hiperemia e da dor local, secreção purulenta de moderada quantidade na conjuntiva tarsal inferior, além do aparecimento de lesões externas, tipo erupções, em pálpebra inferior do mesmo olho (Figura 3).

Na ocasião, a paciente informou que realizara tratamento incompleto para tuberculose pulmonar um ano antes. Desta forma, decidiu-se biopsiar a lesão para investigação de bacilos álcool-ácido resistentes (BAAR) e trocar a medicação para ciprofloxacina oral, até que o resultado fosse concluído.

Porém, após a negatividade do exame investigativo, a paciente lembrou que seus gatos obtiveram o diagnóstico de esporotricose, sendo ela mesma a responsável pelo tratamento dos animais.

Com isso, optou-se por biopsiar novamente a lesão e realizar estudo histopatológico e de cultura para bactérias e fungos do raspado e secreção conjuntivais para confirmar a hipótese etiológica de esporotricose ocular.

Concluiu-se a suspeita clínica levantada com o resultado dos exames que se mostraram positivos para Sporothrix schenckii, sendo então prescrito itraconazol

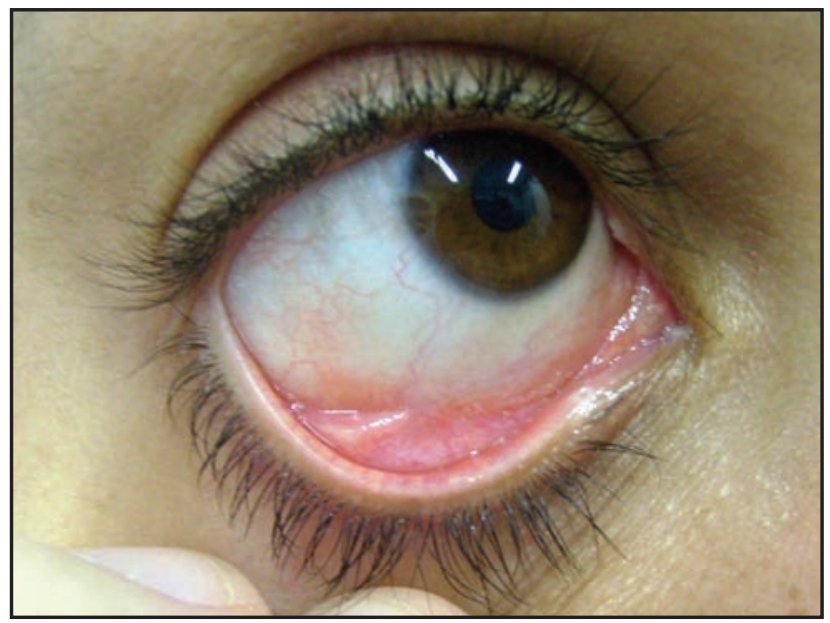

Figura 4: Discreto simbléfaro inferior

oral 100mg/dia e fluconazol colírio 3x/dia.

$\mathrm{O}$ tratamento foi administrado por quatro meses e a paciente acompanhada semanalmente, com documentação por fotos das lesões para comparações seriadas. Após três semanas de tratamento foi possível evidenciar melhora da doença e diminuição das lesões e dos sintomas. Com seis semanas de tratamento a paciente voltou ao trabalho e já não relatava qualquer sintoma.

Após quatro meses, o exame de biomicroscopia em olho direito demonstrou ausência de lesões. Um discreto simbléfaro central em fórnice inferior foi notado como sequela cicatricial da doença, porém sem sintomas associados (Figura 4).

\section{DısCUSSÃO}

A conjuntivite da SOP caracteriza-se classicamente por lesões nodulares na conjuntiva bulbar ou tarsal, evidenciando uma reação granulomatosa, que pode se apresentar de forma branda ou grave, com úlceras ou necrose ${ }^{(3)}$. A adenopatia presente pode ser dolorosa ou não e seu tamanho e consistência variam bastante. Casos atípicos já foram relatados, tais como surgimento de conjuntivite granulomatosa bilateral e ausência de enfartamento ganglionar ${ }^{(4)}$. Outros sinais e sintomas não específicos podem acompanhar a SOP, tais como febre, hiperemia e reação folicular conjuntival, sensação de corpo estranho e secreção mucóide ou purulenta ${ }^{(5)}$.

Até o ano de 1889, a doença tinha sua causa desconhecida, até que Henri Parinaud juntamente com Xavier Galezowski descreveram a síndrome, relatando que se tratava de uma infecção transmitida por animais ${ }^{\left({ }^{(}\right)}$. Desde 
então, diversos agentes etiológicos foram identificados, tais como Chlamydia trachomatis, Listeria monocytogenes, Treponema pallidum ${ }^{(7,8)}$,e Mycobacterium tuberculosis ${ }^{(9,11)}$. Recentemente, alguns fungos foram descritos como causadores da SOP, como Paracoccidioides brasiliensis (12), Cryptococcus neoformans ${ }^{(13)}$, e Sporothrix schenkii ${ }^{(14,15)}$. Alguns vírus como Herpes simplex tipo $1^{(16)}$ e Epstein-Barr (17,18) também foram isolados em pacientes com a síndrome. Nos dias de hoje, porém, o patógeno mais comumente encontrado na SOP é o bacilo gram-negativo Bartonella henselae ${ }^{(4,19)}$, cuja forma de doença mais conhecida é a doença da arranhadura do gato ${ }^{(3,20)}$. A infecção é causada pela inoculação direta do agente causal no olho afetado ${ }^{(21)}$.

O caso descrito, entretanto, mostra uma condição etiológica mais rara. A esporotricose, descrita por Benjamim Schenk em 1898, é causada pelo fungo dimórfico patogênico Sporothrix schenckii ${ }^{(22)}$ que pertence à família Ophiostomataceae, podendo ser encontrado hoje em todo o mundo ${ }^{(23,24)}$. Ela é caracterizada por uma infecção de caráter subagudo ou crônico de ocorrência em humanos e animais, caracterizada por lesões polimórficas dos tecidos cutâneos e subcutâneos, com envolvimento dos canais linfáticos adjacentes, que podem supurar, drenar e ulcerar. A esporotricose se inicia pela inoculação do agente na pele, após contato direto. $\mathrm{O}$ acometimento da conjuntiva ocular da doença se apresenta pela forma de SOP.

Curiosamente, ocorrem importantes mudanças na sua distribuição e incidência desde 1998, especialmente no estado do Rio de Janeiro, segundo dados do Instituto de Pesquisa Clínica Evandro Chagas, da Fundação Oswaldo Cruz ${ }^{(25,26)}$. Desde esse ano, uma grande epidemia da doença é acompanhada e atribuída especificamente ao contato com animais domésticos como cães e, especialmente, gatos domésticos.

As infecções causadas pelo S. schenckii geralmente ocorrem através de ferimentos ou arranhões com espinhos ou farpas de vegetais contaminados e mordeduras e lambeduras de animais infectados, no entanto, alguns casos de infecções sem trauma prévio já foram relatados, mas são $\operatorname{raros}{ }^{(15)}$.

As manifestações clínicas da esporotricose podem ocorrer de diversas formas e a literatura médica ainda diverge quanto à classificação da doença ${ }^{(27)}$. A divisão mais aceita atualmente divide as formas da doença em cutânea e a extracutânea, sendo a primeira a forma mais comum, com $80 \%$ dos casos. O acometimento mucoso é incomum, e acomete preferencialmente a conjuntiva ocular. A síndrome oculoglandular de Parinaud é a re- presentação dessa infecção, que é quase sempre causada por trauma local. O envolvimento intraocular, em contrapartida, ocorre principalmente por disseminação hematogênica ${ }^{(25)}$.

Uma característica da forma cutânea da esporotricose é o desenvolvimento de lesões gomosas no trajeto do ponto de inoculação até o linfonodo regional acometido. No caso aqui descrito, foi observado o surgimento de lesões externas, tipo erupções, em pálpebra inferior, talvez análogas às lesões gomosas da forma cutânea.

O diagnóstico da doença é baseado na detecção direta ou indireta do agente etiológico. No exame direto, o método de coloração pelo gram (gram positivo) pode ser útil na detecção inicial do agente etiológico. $\mathrm{O}$ exame histopatológico também pode ajudar, porém é pouco eficaz se comparado à cultura específica para o fungo.

Exames sorológicos, apesar de pouco usados, têm demonstrado ótima sensibilidade e especificidade na detecção de anticorpos para antígenos do S. schenckii, segundo recentes estudos. A técnica de ELISA (enzyme linked immuno sorbent assay) mostrou uma sensibilidade de $90 \%$ e especificidade de $86 \%{ }^{(28)}$. Esta ferramenta diagnóstica pode ser usada em casos atípicos da doença, em formas generalizadas e aquelas cuja detecção micológica mostrou-se negativa. O teste sorológico é também útil para o follow-up terapêutico dos pacientes.

No tratamento da esporotricose, diversas drogas antifúngicas estão descritas na literatura médica. Iodeto de potássio foi a primeira droga descrita e por muito tempo foi considerada como o medicamento de primeira linha. Outra droga, o itraconazol, tem potente atividade antifúngica contra o Sporothrix schenckii e compartilha seus princípios básicos de atividade com seu predecessor, o cetoconazol. Experimentos em laboratório demonstraram uma superioridade do itraconazol contra o S. schenckii em relação ao cetoconazol. A dose de $100 \mathrm{mg} /$ dia pelo período mínimo de 3 meses tem demonstrado bons resultados na literatura, mas em alguns casos a dose pode chegar a $400 \mathrm{mg} / \mathrm{dia}$. O fluconazol é uma alternativa terapêutica, porém não é usada como primeira opção e a terbinafina não é uma droga formalmente indicada no tratamento da esporotricose, já que poucos estudos publicados mostraram sucesso com essa medicação in vivo ${ }^{(29)}$. A anfotericina $\mathrm{B}$ por via endovenosa permanece a droga de escolha para a esporotricose sistêmica e dissemina- 
da da doença, além dos casos que não responderam com as drogas descritas acima.

A esporotricose é uma doença geralmente de bom prognóstico até mesmo quando acomete imunocomprometidos. A rapidez no diagnóstico da doença e a escolha da melhor opção terapêutica aceleram a melhora do paciente e diminuem as chances de complicações.

\section{CONCLUSÃo}

Por ser uma doença considerada rara, a síndrome oculoglandular de Parinaud pouco é lembrada no dia a dia do oftalmologista. Entretanto, em casos de conjuntivites com reação granulomatosa evidente e acometimento linfonodal, esta síndrome deve ser lembrada. Na história clínica do paciente, o conhecimento de doenças prévias, profissão e dados epidemiológicos são de grande valia para o direcionamento da hipótese etiológica, escolha do melhor método complementar de diagnóstico, assim como na determinação da conduta terapêutica apropriada.

Como a bartonellose se mostra como a grande causadora desta doença, o tratamento empírico para essa infecção pode ser estabelecido, principalmente em caso de história prévia de contato com gatos. Ainda assim, o caso relatado mostrou que agentes incomuns não devem ser negligenciados e por isso devem ser considerados diante da SOP, ainda que sejam atípicos. No caso descrito, tanto a anamnese quanto o acompanhamento foram cruciais para a identificação do Sporothrix schenkii e seu bem-sucedido tratamento.

\section{Abstract}

Parinaud's oculoglandular syndrome is a rare eye disease caused by different pathogens, including bacteria, viruses and fungi. It is characterized by a granulomatous conjunctivitis with adjacent preauricular lymphadenopathy and can cause sequelae if not promptly treated. We report a case of a young nurse assistant and veterinary student showing Parinaud's oculoglandular syndrome caused by the fungus Sporothrix schenkii after contamination with infected cats. Its clinical presentation and negative outcome until the correct ethiological diagnosis, in addition to specific treatment, emphasize the importance of laboratory investigations in cases of atypical development of the disease.

Keywords: Conjunctivitis, bacterial/diagnosis;
Conjunctivitis, bacterial/etiology; Granuloma/diagnosis; Granuloma/etiology; Cat-scratch disease/complications; Bartonella henselae; Sporotrichosis

\section{ReferêNCIAS}

1. Huang MC, Dreyer E. Parinaud's oculoglandular conjunctivitis and cat-scratch disease. Int Ophthalmol Clin. 1996;36(3):29-36.

2. Yamashita CA, Mielle A, Renko NS, Nascimento S, Gilio A, Pahl M, et al. Parinaud syndrome caused by bartonella henselae: case report. Rev Inst Med Trop Sao Paulo. 1996;38(6):437-40.

3. Barnes C, Foster C. Bacterial conjunctivitis. In: Foster CS, Azar DT, Dohlman CH, editors. Smolin and Thoft's The cornea: Scientific Foundations and Clinical Practice. 4th ed. Philadelphia: Lippincott Williams \& Wilkins; 2005.

4. Oliveira AH, Pereira CA, Souza LB, Freitas D. Conjuntivite granulomatosa atípica causada pela doença da arranhadura do gato: relato de caso. Arq Bras Oftalmol. 2004;67(3):541-3.

5. Rapuano CJ, Kim T, Luchs JI. Anterior segment: the requisites in ophthalmology. Missouri: Elsevier Health Sciences; 1999. Conjuntiva and external disease; p.1-45.

6. Koppejan EH. Parinaud's Syndrome. In: Koehler P, Bruyn G, Pearce J, editors. Part IV Syndromes: neurological eponyms. Oxford: Oxford University Press; 2000. p.239-43.

7. Margileth AM. Cat scratch disease. In: Behrman RE, Kliegman RM, Arvin AM. Nelson textbook of pediatrics. Philadelphia: WB Saunders; 1996. p.865-7

8. Thorell EA, Chesney PJ. Cervical lymphadenitis and neck Infections. In: Long SS, Pickering LK, Prober CG. Principles and practice of pediatric infectious disease. 3rd ed. Maryland Heights (MO): Churchill Livingstone; 2008. Chapter 19.

9. Sollom AW. Primary conjunctival tuberculosis. Br J Ophthalmol. 1967;51(10):685-7.

10. Thompson MJ, Albert DM. Ocular tuberculosis. Arch Ophthalmol. 2005;123(6):844-9.

11. Archer D, Bird A. Primary tuberculosis of the conjunctiva. Br J Ophthalmol. 1967;51(10):679-84.

12. Costa PS, Hollanda BV, Assis RV, Costa SM, Valle LM. Parinaud'S oculoglandular syndrome associated with paracoccidioidomycosis. Rev Inst Med Trop Sao Paulo.2002;44(1):49-52.

13. Souza MB, Melo CS, Silva CS, Santo RM, Matayoshi S. Criptococose palpebral: relato de caso. Arq Bras Oftalmol. 2006;69(2):265-7.

14. Thomas PA. Current perspectives on ophthalmic mycoses. Clin Microbiol Rev. 2003;16(4):730-97.

15. Schubach A, de Lima Barros MB, Schubach TM, Francesconido-Valle AC, Gutierrez-Galhardo MC, Sued M,et al. Primary conjunctival sporotrichosis: two cases from a zoonotic epidemic in Rio de Janeiro, Brazil. Cornea. 2005;24(4):491-3.

16. Caputo GM, Byck H. Concomitant oculoglandular and ulceroglandular fever due to herpes simplex type I. Am J Med. 1992;93(5):577-80.

17. Meisler DM, Bosworth DE, Krachmer JH. Ocular infectious mononucleosis manifested as Parinaud's sculoglandular Syndrome. Am J Ophtalmol. 1981;92(5):722-6.

18. Matoba AY. Ocular disease associated with Epstein-Barr virus infection. Surv Ophtalmol. 1990;35(2):145-50.

19. Piémont Y, Heller R. [Bartonellosis: I. Bartonella henselae]. Ann Biol Clin (Paris). 1998;56(6):681-92. 
20. Regnery R, Tappero J. Unraveling mysteries associated with cat-scratch disease, bacillary angiomatosis, and related syndromes. Emerg Infect Dis. 1995;1(1):16-21.

21. Grando D, Sullivan LJ, Flexman JP, Watson MW, Andrew JH. Bartonella henselae associated with Parinaud's oculoglandular syndrome. Clin Infect Dis. 1999;28(5):1156-8.

22. Hektoen L, Perkins CF. Refractory subcutaneous caused by Sporothrix Schenckii: a new pathogenic fungus. J Exp Med. 1900; 5(1):77-89.

23. Rippon JW. Medical mycology: the pathogenic fungi and the pathogenic actinomycetes. 3rd ed. Philadelphia: WB Saunders; 1988. Sporotrichosis; p.325-52.

24. Lyon GM, Zurita S, Casquero J, Holgado W, Guevara J, Brandt ME, et al. Population-based surveillance and a case-control study of risk factors for endemic lymphocutaneous sporotrichosis in Peru. Clin Infect Dis. 2003;36(1):34-9.

25. Schubach A, Barros MB, Wanke B. Epidemic sporotrichosis. Curr Opin Infect Dis. 2008;21(2):129-133.

26. Schubach AO, Schubach TM, Barros MB. Epidemic cat-transmitted sporotrichosis. N Engl J Med. 2005;353(11):1185-6.
27. Lacaz CS, Porto E, Martins JE, Heins-Vaccari E, Melo N. Tratado de micologia médica Lacaz. 9a ed. São Paulo: Sarvier; 2002 .

28. Bernardes-Engemann AR, Costa RC, Miguens BR, Penha CV, Neves E, Pereira BA, et al. Development of an enzyme-linked immunosorbent assay for the serodiagnosis of several clinical forms of sporotrichosis. Med Mycol. 2005;43(6):487-93.

29. Meinerz AR, Nascente OS, Schuch LF, Cleff MB, Santin R, Brum CS, et al. Suscetibilidade in vitro de isolados de Sporothrix Schenckii frente à terbinafina e itraconazol. Rev Soc Bras Med Trop. 2007; 40(1):60-2.

\section{Endereço para correspondência} Alexandre Sampaio de Abreu Ribeiro

Estrada da Gávea, no 681, Bloco 2, Ap.1301

São Conrado - Rio de Janeiro - RJ

CEP 22610-001

Telefones: 3322-4363 / 9762-2901 